\title{
Reliability and Validity of Nurses' Experiences of Infection Prevention and Control Questionnaire
}

\author{
Eda Aktas $^{1}$ (D), Cagri Covener Ozcelik ${ }^{2}$ (D) Ayse Ferda Ocakci ${ }^{3}$ (D) \\ ${ }^{1}$ University of Health Sciences, Hamidiye Faculty of Nursing, Department of Pediatric Nursing, Istanbul, Turkey. \\ ${ }^{2}$ Marmara University, Faculty of Health Sciences, Department of Nursing, Pediatric Nursing Division, Istanbul, Turkey. \\ ${ }^{3}$ Koc University, Faculty of Nursing, Istanbul, Turkey.
}

Correspondence Author: Eda Aktas

E-mail: eda.aktas@sbu.edu.tr

Received: 13.11 .2019

Accepted: 02.04 .2020

\begin{abstract}
Objective: Nosocomial infections are the primary reason of morbidity and mortality especially at children's hospitals. Thus, educating pediatric health care providers is rather crucial in order to protect children from exposure to infection. This study was planned to examine reliability and validity of Nurses' Infection Prevention and Control Observation Questionnaire in Turkish Language.

Methods: This methodological study was carried out at a randomly selected Children's Hospital from each of the 7 regions of Turkey. In total, 443 pediatric nurses from those hospitals participated in the study. Content validity, construct validity, inter-consistency reliability and item total correlation of the questionnaire were analysed in order to adjust reliability and validity.

Results: The questionnaire has good content, face and construct validity. The acceptable level for scales' items was above 0.30 and had one factor according to results of explanatory factor analysis. The questionnaire model fitted the data according to confirmatory factor analysis. A level of Cronbach's alpha at 0.74 was considered to be an acceptable level of reliability and item-total score correlation of the study-except for four items - was identified above 0.30 .

Conclusion: The questionnaire was determined as a reliable and validate tool in evaluation of observation for nurses' infection prevention and control.

Keywords: Infection control, pediatric nurse, validity, reliability
\end{abstract}

\section{INTRODUCTION}

Nosocomial infections are among the most frequently reported problems arising in the provision of healthcare services the world over $(1,2)$. Nosocomial infections represent the most significant health challenges to modern medicine in the broader sense that 'healthcare service-related infections' are one of the most important healthcare problems in modern medicine that are predictable and manageable (35). It has been estimated that nosocomial infections develop in 1.4 million people every day (6).

Nosocomial infections are not only a source of morbidity and mortality for patients, they also represent a serious financial loss for the countries involved (6-7). The key risk factors leading to nosocomial infections are:

- Interventional implementations at the hospital,

- Poor cleaning,

- Physical shortages,
- Insufficient number of personnel and

- Negative factors affecting the patient's immune system (7).

Risk factors leading to the development of nosocomial infection usually occur due to ignoring infection control principles (infrastructure insufficiency of hospitals, inadequate and uneducated healthcare providers, poor hand hygiene compliance by healthcare providers and their use of inappropriate types of medical gloves, unnecessary invasive interventions and not adhering to asepsis and antisepsis protocols) $(5,7,8)$.

Nosocomial infection is the primary reason for morbidity and mortality, especially in children's hospitals (9). Thus, educating paediatric healthcare providers is crucial in order to protect children from exposure to infection. Since the number of brief and easily understood questionnaires is 
limited in the Turkish language, this study aimed to prove the reliability and validity of the Nurses' Infection Prevention and Control Observation Questionnaire in the Turkish language.

\section{METHODS}

\subsection{Type of Study}

The study was methodological design.

\subsection{Participants}

The study was conducted at children's hospitals which were randomly selected from each of the 7 regions of Turkey. A total of 443 pediatric nurses working at these hospitals participated in the study. The inclusion criteria were a) having at list 1 month of clinical experience and holding a permanent position in the pediatric department, b) working full time, c) voluntarily signing the informed consent form

\subsection{Measurements}

Nurse Descriptive Information Form: This form consists of a total of 8 items, 5 close-ended questions and 3 open-ended questions and includes the sociodemographic characteristics of nurses working at the paediatric clinics. It was designed to be compatible with similar forms found in the literature.

Nurses' Infection Prevention and Control Observation Questionnaire: The questionnaire was developed to determine the observations of intern nurses on infection control and prevention. It consists of a total of 19 items, designed as a 5-point Likert-like questionnaire and scored as follows: 1 = never, 2 = not often, 3 = do not know/cannot remember, $4=$ often and $5=$ witnessed poor practice very often. The lowest score shows positive infection prevention behaviour. Gould et al. (2013) designed the items of the questionnaire, but validity and reliability analyses were not performed.

\subsection{Data Collection}

The required data were gathered from March 2014 to June 2015. The questionnaire was posted to relevant hospitals, and then the hospitals re-posted the questionnaires to the researchers. The study did not incur any loss of data.

\subsection{Ethical Considerations}

Required permissions were obtained from the Ethic Committee of Koc University (21.10.2013, 2013.209. IRB3.142). Participants were informed that the study was conducted solely for scientific means and that the data obtained from the study would never be shared with third parties. The participants confirmed their participation with their written approvals.

\subsection{Statistical Analysis}

Number Cruncher Statistical System (NCSS) 2007 Software (Utah, USA) was utilized to analyse the data. For validity analysis, the language validity, content validity and construct validity were tested. Explanatory factor analysis (EFA) and confirmatory factor analysis (CFA) were used to test the construct validity. Cronbach's alpha coefficient and itemtotal score correlation were calculated for reliability analysis. Further, sociodemographic data were calculated using descriptive statistical methods (averaging, standard deviation (SD) and percentage).

\section{RESULTS}

Mean ages of the participants were $30.76 \pm 6.56(18-52)$ years, and the duration of their professional career at clinics was $7.49 \pm 7.06$ ( 1 month to 34.41 years) years. A total of $87.4 \%(n=387)$ of the participant nurses were females, and $12.6 \%(n=56)$ were males.

\subsection{Validity}

\subsubsection{Linguistic validity}

The questionnaire was first translated from English to Turkish separately by two bilingual linguistic experts experienced in medical and nursing texts. The scales were then translated back from Turkish to English by two other bilingual language experts. The back-translated and original scales were compared, and they were found to be highly similar in terms of meaning. This completed the language validation.

\subsubsection{Face validity}

A pilot study was conducted with 30 paediatric nurses to ensure face validity. No changes in the questionnaire were deemed necessary.

\subsubsection{Content validity}

The Turkish scales were presented to 10 experts in communicable disease nursing and health sciences in order to test intelligibility and compatibility with the culture; content validity was ensured by making minor changes, such as word or sentence corrections, based on their suggestions. The content validity index (CVI) was calculated. The experts were asked to rate each item on a 4-point scale ( $1=$ not relevant, 2 = somewhat relevant, 3 = quite relevant and $4=$ highly relevant) according to the Davis technique (10). Then, for each item, item-CVI (I-CVI) was computed as the number of experts stating a rating of either 3 or 4 , divided by the total number of experts. If $80 \%$ of the experts rated the item 3 or 4 , the I-CVI score was 0.80 . Then, the mean I-CVI was calculated across items for the questionnaire-CVI (Q-CVI) (11). The $\mathrm{Q}-\mathrm{CVI}$ of the form was 1.0. Also, Kendall's $\mathrm{W}$ concordance analysis was utilized to assess content validity and was found to be concordant among the experts (Kendall's W $=0.221$, df $=18, c^{2}=19.92, p=0.337$ ). 


\subsubsection{Construct validity}

EFA was applied to ensure construct validity. The Kaiser-MeyerOlkin (KMO) measure was 0.80 , indicating the applicability of EFA. Bartlett's test of sphericity was statistically significant $\left(\chi^{2}=1220.27 ; p=0.000\right)$. According to the results of factor analysis, the questionnaire had one factor and explained $21.63 \%$ of total variance. The acceptable level for the scales' items was above 0.30 according to the results of the EFA (Table 1).

Table 1. Characteristics of Nurses' Infection Prevention and Control Observation Questionnaire

\begin{tabular}{|c|c|c|}
\hline Items & $\begin{array}{l}\text { Factor } \\
\text { load }\end{array}$ & $\begin{array}{l}\text { Item to total } \\
\text { correlations }\end{array}$ \\
\hline $\begin{array}{l}\text { 1) Not cleansing hands between patient } \\
\text { contacts }\end{array}$ & 0.39 & 0.33 \\
\hline 2) Wearing rings (excluding wedding bands) & 0.44 & 0.30 \\
\hline $\begin{array}{l}\text { 3) Failure to apply isolation precautions (eg, } \\
\text { not wearing PPE) }\end{array}$ & 0.59 & 0.50 \\
\hline $\begin{array}{l}\text { 4) Poor cleaning (eg, lockers, trolleys, baths, } \\
\text { wash bowls) }\end{array}$ & 0.54 & 0.44 \\
\hline $\begin{array}{l}\text { 5) Not changing personal protective clothing } \\
\text { between patients }\end{array}$ & 0.47 & 0.39 \\
\hline $\begin{array}{l}\text { 6) Poor practice "sharps" management (eg, } \\
\text { resheathing) }\end{array}$ & 0.55 & 0.43 \\
\hline $\begin{array}{l}\text { 7) Using mobile telephones during patient } \\
\text { contact }\end{array}$ & 0.41 & 0.30 \\
\hline $\begin{array}{l}\text { 8) Reusing items without cleaning between } \\
\text { patients }\end{array}$ & 0.46 & 0.35 \\
\hline 9) Items stained with blood or body fluids & 0.45 & 0.32 \\
\hline 10) Not being "bare below the elbow" & 0.34 & 0.27 \\
\hline $\begin{array}{l}\text { 11) Dealing with body fluids without wearing } \\
\text { gloves }\end{array}$ & 0.58 & 0.45 \\
\hline $\begin{array}{l}\text { 12) Poor practice in relation to urinary } \\
\text { catheters (eg, disconnecting catheter from } \\
\text { drainage system) }\end{array}$ & 0.57 & 0.41 \\
\hline $\begin{array}{l}\text { 13) Reuse of scissors during dressing } \\
\text { procedures without cleaning }\end{array}$ & 0.33 & 0.22 \\
\hline $\begin{array}{l}\text { 14) Poor management of intravenous therapy } \\
\text { (eg, disconnecting lines from access device) }\end{array}$ & 0.53 & 0.39 \\
\hline $\begin{array}{l}\text { 15) Inappropriate storage of sterile items (eg, } \\
\text { torn or dusty outer wrapping) }\end{array}$ & 0.48 & 0.32 \\
\hline 16) Reuse of single-use item & 0.40 & 0.27 \\
\hline $\begin{array}{l}\text { 17) Insertion of a urinary catheter without } \\
\text { gloves }\end{array}$ & 0.46 & 0.28 \\
\hline
\end{tabular}

However, CFA was performed to test for construct validity. The factor model fitted the data $(p=0.000)$. Goodness of fit statistics follow: the root mean square error of approximation (RMSEA) was 0.066; comparative fit index (CFI) was 0.90; incremental fit index (IFI) was 0.90; root mean square residual (RMR) was 0.037, goodness of fit index (GFI) was 0.91 and $\chi^{2} /$ df index was 3.11, respectively (Fig. 1).

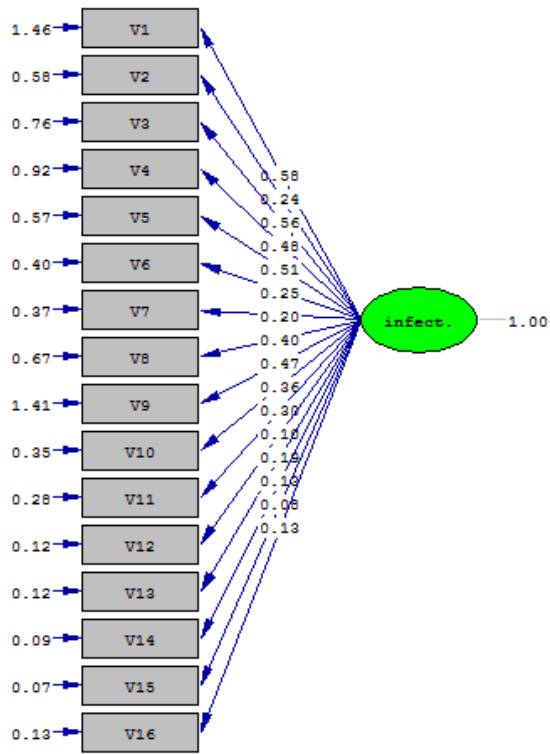

Chi-Square $=303.41, \mathrm{df}=104, \mathrm{P}$-value $=0.00000, \mathrm{RMSEA}=0.066$

Figure 1. Path Diagram of Confirmatory Factor Analysis for Nurses' Infection Prevention and Control Observation Questionnaire

\subsection{Reliability}

The results of item-total score correlation are presented in Table 1. Cronbach's alpha coefficient of the questionnaire was determined as 0.74 .

\section{DISCUSSION}

In the original text of the Nurses' Infection Prevention and Control Observation Questionnaire, validity and reliability analysis had not been performed (1). Consequently, in the Turkish adaptation of the questionnaire, validity and reliability analyses were performed using various methods.

Content validity refers to how accurately an assessment or measurement tool taps into the various aspects of the specific construct in question (11). In this case, the CVI was calculated. A CVI score of 0.80 or above means that all experts are in agreement about relevance. The Q-CVI of the form was 1.0, which means that the form has an acceptable content validity. However, according to Kendall's W concordance analysis, no meaningful difference was detected among the views of the experts. These results show that the questionnaire is appropriate for the Turkish culture.

Construct validity assesses how much the tool reached its goal to measure an abstract concept, difficult-to-measure behaviour or dimension. In the present study, explanatory and confirmatory factor analyses were utilized to ensure construct validity. EFA is a statistical method used to obtain information on the nature of the tool and factors being measured instead of testing a particular hypothesis (11). 
According to KMO measure for sampling adequacy test values, $0.60-0.69$ represents 'average', $0.70-0.79$ is 'good', $0.80-0.89$ is 'very good' and $0.90-1.00$ is 'perfect'. Bartlett test evaluates the appropriateness of items for factor analysis (12). The value of 0.80 'very good' for the KMO measure for sampling adequacy test and $p=0.000$ for the Bartlett test indicate that the results are statistically significant. Based on the findings, it may be concluded that the sample of the present study is appropriate for factor analysis. Factor loads ranged from 0.33 to 0.59 . Factor loads were at acceptable levels as they were found above 0.30 (13). Two items were removed from the questionnaire because their factor loads were under 0.30 . Although the original questionnaire has 19 items, the adapted questionnaire has 17 items.

CFA is a multivariate statistical procedure used to test whether the measured variables represent the number of constructs (11). The RMSEA fit index is used to assess goodness of fit statistics in CFA, with RMSEA $\leq 0.05$ showing a perfect fit, while RMSEA $\leq 0.08$ shows a good fit (14). The RMSEA value of the questionnaire was 0.066 , which indicated a good fit. $\mathrm{CFI} \geq 0.95$ shows a perfect fit, and CFI $\geq 0.90$ shows a good fit. The CFI fit index of the questionnaire, 0.90, represents a good fit. Another fit index is the IFI where $\geq 0.95$ shows perfect fit, and IFI $\geq 0.90$ shows a good fit (15). The IFI fit index of the questionnaire, 0.90 , means a good fit. On the other hand, RMR fit index is a perfect fit if it is $\leq 0.05$, and $\leq 0.08$ is a good fit. In this study, the RMR index was 0.037 , which shows a perfect fit. Another fit index, GFI, means a good fit if the value is $\geq 0.90$, so the GFI fit index of the questionnaire, 0.91 , represents a good fit. Similarly, a $\chi^{2} / \mathrm{df}$ fit index of $\leq 3$ shows a perfect fit, and $\leq 5$ shows an acceptable model fit (14). The $\chi^{2} / \mathrm{df}$ value for the questionnaire was 2.92, indicating a perfect fit. The questionnaire model fitted the data according to CFA.

Reliability refers to ensuring determinedness, adequacy, equality, consistency and stability (11). They are known as test-retest, parallel or alternate form, item-total correlation, split-half, Kuder-Richardson (KR-20), Cronbach's alpha and interrater reliability (16). In the present study, Cronbach's alpha reliability coefficient and item-total score correlation were used to analyse reliability. Cronbach's alpha coefficient of the study was determined as acceptable. A Cronbach's alpha coefficient of 0.70 or higher is considered to be acceptable for reliability $(12,16)$.

The item-total score correlation of the study, except for four items, was identified as above 0.30 . It was suggested in some sources that the correlation coefficient of the items should be higher than 0.30 and those items with lower values should be removed $(11,12)$. The item-total score correlation value of four items ranged from 0.22 to 0.28 . However, those items' factor loads were from 0.33 to 0.46 , so researchers decided not to remove them in order not to ensure the integrity of the questionnaire.

\section{Strengths and Limitations of The Study}

The sample of the study included 443 paediatric nurses. It has been stated that reliability and validity analysis should include 5 to 10 times more participants than the total number of the items (11). Even though 190 participants would have been enough for the present study, it was conducted with a total of 443 participants. Findings of the study can be generalized to the country since the participants were selected from seven different regions in Turkey. All the reliability and validity analyses resulted in acceptable levels. However, the most significant limitation of the study was that it was carried out only with paediatric nurses working at children's hospitals.

\section{CONCLUSION}

These results indicated that this scale is a valid and reliable questionnaire. It is an useful questionnaire for evaluation of observation for nurses' infection prevention and control. Pediatric nurses can easily use this questionnaire. In addition, since, there is limited number of infection scales, this scale could be used in future studies and education programmes for nurses aiming at changing their behaviours and attributes.

\section{REFERENCES}

[1] Gould D, Drey N. Student nurses' experiences of infection prevention and control during clinical placement. Am J Infect Control 2013;41(9):760-763.

[2] Kaier K, Wilson C, Hulscher M, Wollersheim H, Huis A, Borg M, Scicluna E, Lambert ML, Palomar M, Tacconelli E, De Angelis G, Schumacher M, Wolkewitz M, Kleissle EM, Frank $U$. Implementing bundles for infection prevention and management. J Infect 2012;40(2):225-228.

[3] Jackson C, Lowton K, Griffiths P. Infection prevention as "a show": a qualitative study of nurses' infection prevention behaviours. Int J Nurs Stud 2013;51(3):400-408.

[4] Öztürk R. Hastane Enfeksiyonları: Sorunlar, Yeni Hedefler ve Hukuki Sorumluluk. In: Öztürk R, Saltoğlu N, Aygün G, editors. Hastane Enfeksiyonları Korunma ve Kontrol. İstanbul: Ohan Matbaacılık; 2008; pp.23-29 (Turkish).

[5] Pittet, D. The Lowbury lecture: behaviour in infection control. J Hosp Infect 2004;58(1):1-13.

[6] Alp E. Hastane enfeksiyonları tanımı, epidemiyolojisi ve risk faktörleri. In: Enfeksiyon Kontrol Programı. Kayseri: Erciyes Üniversitesi Hastaneleri Yayın No:55; 2012:5-7. (Turkish).

[7] Gürkan Karakuş Z, Ulupınar S. İnfeksiyon kontrol hemşirelerinin yaşadıkları güçlükler. Flora 2009;14(3):128-138.

[8] Morrow E, Griffiths P, Rao GG, Flaxman D. "Somebody else's problem": staff attributions of cause and risk of meticillinresistant staphylococcus aureus. Am J Infect Control 2011;39(4):284-291.

[9] Pourakbari B, Rezaizadeh G, Mahmoudi S, Mamishi S. Epidemiology of nosocomial infections in pediatric patients in an Iranian referral hospital. J Prev Med Hyg 2012;53(4):204206.

[10] Davis LL. Instrument review: getting the most from a panel of experts. Applied Nursing Research 1992; 5:194-197. 
[11] Esin NM. Veri Toplama Yöntem ve Araçları \& Veri Toplama Araçlarının Güvenirlik ve Geçerliği. In: Erdoğan S, Nahcivan N, Esin MN, editors. Hemşirelikte Araştırma. 1. Baskı. İstanbul: Nobel Tıp Kitabevi; 2014. pp.193-233 (Turkish).

[12] Tavşancıl, E. Tutumların Ölçülmesi ve SPSS ile Veri Analizi. 3. Baskı. İstanbul: Nobel Yayın Dağıtım; 2006 (Turkish).

[13] Şencan H. Cronbach Alfa Güvenirlilik Analizleri. In: Güvenirlik ve Geçerlilik. 1. Baskı, Ankara: Seçkin Yayıncılık; 2005. pp.230-247 (Turkish).
[14] Çokluk Ö, Şekercioğlu G, Büyüköztürk Ş. Sosyal Bilimler için Çok Değişkenli İstatistik SPSS ve LISREL Uygulamaları. 14. Basım. Ankara: Pegem Akademi; 2014 (Turkish).

[15] Seçer i. Psikolojik Test Geliştirme ve Uyarlama Süreci SPSS ve LISREL Uygulamaları. 1. Baskı. Ankara: Anı Yayıncılık; 2012. pp. 98 (Turkish).

[16] Haber J, LoBiondo-Wood G. Reliability and validity. In: LoBiondo Wood G, Haber J, editors. Nursing research methods and critical appraisal for evidence-based practice. 6th ed. Missouri: Mosby Elsevier; 2006. pp.335-356. 